\title{
Deleterious MLH1 Gene Mutation
}

National Cancer Institute

\section{Source}

National Cancer Institute. Deleterious MLH1 Gene Mutation. NCI Thesaurus. Code C131779.

A change in the nucleotide sequence of the MLH1 gene that is associated with increased risk of disease. 